\title{
Leger, bøker og medisinsk kunnskap i Norge rundt 1700
}

\author{
Sammendrag \\ Medisinens utvikling i den tidlig \\ moderne periode $(1500-1800)$ la \\ grunnen for vår moderne medisin \\ ved at blant annet (iatro)kjemiske og \\ mekanistiske kroppsoppfatninger etter \\ hvert fikk større betydning for lege- \\ vitenskapen. \\ Det er likevel ikke snakk om at medi- \\ sinen endret seg over natten. I stedet \\ ble flere medisinske teorier brukt og \\ testet ut side om side. Få studier er \\ hittil blitt gjort med tanke på å belyse \\ hvilket kunnskapsunivers leger i Norge \\ i denne perioden befant seg i. \\ I denne artikkelen vil jeg presentere \\ boksamlingene til legene Jacob Wol- \\ denberg, Georg Blumenthal og Paul \\ Dons, utdannet rundt 1700 , for å se \\ hvordan disse forholdt seg til den tidlig \\ moderne medisinens mangfold. \\ Sett under ett dekket alle de tre bok- \\ samlingene både antikke medisinske \\ teorier samt de nye debattene innenfor \\ legevitenskapen. Brorparten av bøkene \\ kom likevel fra Tyskland og Nederland, \\ hvilket vil si at disse tre legene sto i en \\ tysk, og dernest nederlandsk, lær- \\ domstradisjon.
}

\section{Gina Dahl}

gina.dahl@ahkr.uib.no

Institutt for arkeologi, historie, kultur-

og religionsvitenskap

Universitetet i Bergen

Øysteinsgate 3

5007 Bergen

Tiden 1650-1800 er blitt betegnet som en periode preget av eklektisme innenfor medisinen. Fremdeles var antikkens læremestre, som Hippokrates og Galen (fig 1), viktige. Den teoretiske overbygningen i antikkens medisin var humoralpatologien og dens fire væsker: blod, slim, gul galle og svart galle. Disse væskene ble koblet til naturelementene ild, luft, jord og vann og til kvalitetene kulde, varme, tørrhet og fuktighet. Innenfor dette systemet ble sykdom sett på som ubalanse mellom kroppsvæsker (dyskrasi). Balanse kunne gjenvinnes ved bruk av årelating, svettekurer og brekkmidler, og helt frem til renessansen var humoralpatologien enerådende innenfor medisinen.

I den tidlig moderne perioden ble humoralpatologien kraftig utfordret av den nye anatomien. Kroppsforståelsen ble blant annet radikalt endret gjennom arbeidene til Thomas Willis (1621-75) (nervesystemet), William Harvey (1578-1657) (blodsirkulasjonen) og Richard Lower (1631-91) (respirasjonen). Også i Danmark endret anatomer som Niels Steensen (1638-86) og Thomas Bartholin (1616-80) sentrale dogmer innenfor den galenske anatomi.

I tillegg oppsto det fra 1600-tallet av to medisinske systembygninger som fra hvert sitt hold tilbød alternative forklaringer til den galenske modell. Den ene, iatrokjemien (iatro = lege), forfektet at kroppen kunne forstås ut fra kjemiske prinsipper. Retningen hadde sine røtter i alkymien slik den ble utformet av Paracelsus (1493-1541), og viktige representanter var Joan Baptista van Helmont (1579-1644) og Franciscus Sylvius (1614-1672) (fig 2). I DanmarkNorge ga man på 1600-tallet ut flere farmakopeer som inkluderte kjemisk fremstilte medikamenter (2), og den danske legen Peder Sørensen (1540-1602) var en av Paracelsus' mest berømte tilhengere.

Det andre systemet, iatromekanikken, var grunnlagt på matematiske og mekaniske prinsipper. Et viktig teoretisk grunnlag her var gjenoppdagelsen av Lucretius' (ca. 95-ca. 55 f.Kr.) De rerum natura som gjenintroduserte atomistiske doktriner i Vesten. Fremtredende iatromekanikere var Friedrich Hoffmann (1660-1742) og Hermann Boerhaave (1668-1738). Dette systemet fikk sitt for samtiden kanskje mest provoserende uttrykk i Julien Offray de La Mettries (1709-51) ideer om at mennesker var en maskin - menneskemaskinen (l'homme machine), som handlet i tråd med matematiske prinsipper. På grunnlag av den ovenfornevnte utviklingen formulerte Thomas Willis tre måter å klassifisere den tidlig moderne medisinen på: den aristoteliske, den epikureiske (eller mekaniske) og den kjemiske (3).

\section{Legene og kildematerialet}

Med dette teoretiske mangfoldet i mente skal jeg nå ta noen dypdykk ned i boksamlingene til tre leger som praktiserte i Norge rundt 1700 for å belyse hvordan nettopp disse forholdt seg til samtidens motstridende medisinske teorier. Analysen av legenes boksamlinger baserer seg på bokopptegnelser slik de står listet i en skifteprotokoll (Blumenthal) (fig 3), en auksjonsprotokoll (Woldenberg) og en bokkatalog (Dons). Selve samlingene finnes ikke lenger. Utvalget av boksamlinger er foretatt på et rent pragmatisk grunnlag: Det finnes svært få opptegnelser av legers biblioteker i perioden, noe som gjør disse boksamlingene unike, da de er indikatorer på hva leger i Norge leste og hva man kunne få tak i av medisinsk litteratur tidlig på 1700tallet. En mindre studie er gjort av boksamlingen til legen og læreren i fysikk ved Christiania Gymnasium, Ambrosius Rhodius' (1605-96) boksamling (4).

Siden det her kun dreier seg om tre boksamlinger, gjør ikke boksamlingene krav på noen form for representativitet. Men, som

\section{Hovedbudskap}

- Medisinske boksamlinger gir oss verdifull informasjon om legers teoretiske og praktiske orientering

- Studiet av tre norske legers boksamlinger speiler at medisinen rundt år 1700 i stor grad var preget av teoretisk og praktisk eklektisme

- På bakgrunn av boksamlingene kan legene sies å ha stått primært i en tysk, dernest nederlandsk, lærdomstradisjon 
jeg vil vise i det som følger, er visse grunnleggende trekk felles for boksamlingene, noe som gjør det mulig å formode at en del av det som avdekkes her også vil gjelde for andre legers kunnskapstilfang i samme periode.

De tre legene hvis boksamlinger behandles i denne artikkelen, ble utdannet i perioden 1670-1733. Jacob Woldenberg (1649-1735) ble født i København. Han mottok doktorgraden ved universitetet i København i 1679 og ble deretter lege i hæren. I 1686 ble han utnevnt til botanicus i Norge, og i perioden 1686-87 tjente han som lege i Kongsberg. I 1688 ble han stadsfysikus i Bergen, en stilling han ble i frem til sin død (5, bind 9 s. 165-6). På tross av sin lange tjenestetid har Woldenberg kun etterlatt seg noen få brev. I disse klager han over at barberere, jordmødre og prestekoner ikke respekterte legens monopol på å kurere indre sykdommer (6).

Georg Henrich Blumenthal (1687-1742) studerte ved universitetet i København 40 år etter Woldenberg. Han vokste opp i Tyskland og startet sine medisinske studier i Luneburg. Senere ble han kirurg på en hvalfangstskute som seilte langs Grønlandskysten. I 1710 bosatte han seg i Danmark hvor han virket som kirurg for den danske flåten. Blumenthal hadde imid- lertid akademiske pretensjoner: I 1725 ble han immatrikulert ved universitetet i København, og han ble kreert doktor i medisin i 1733. Fra 1736 og frem til han døde i 1742, virket han som lege i Kongsberg (5, bind 1 s. 472).

Paul Dons (1689-1748), ble født i Trondheim og praktiserte som lege i hjembyen. Dons studerte i København ved Ehlers Collegium (1710-11) og Borchs Collegium (1711-15) og tjente deretter som assistentlege ved Kvæsthuset. Vel hjemme i Trondheim avanserte Dons fort også innenfor byadministrasjonen. Blant annet ble han valgt til borgermester i 1733, og han jobbet også som dommer. Dons fortsatte likevel i sin stilling som stadsmedicus (7). Vi vet lite om hvordan Dons praktiserte som lege.

\section{Boksamlingene og deres innhold}

Av de tre bokeierne eide Dons den desidert største samlingen. Den talte i alt ca. 580 bøker (8), men mange av disse var ikke av medisinsk karakter. Woldenbergs boksamling var på ca. 300 bøker (9), Blumenthals på ca. 160 bind (10). Antallet verker som listes i denne typen materiale kan ikke alltid eksakt gjengis pga. unøyaktig registrering.

Sett under ett ser det ut som om visse områder var spesielt viktig for distribusjonen av medisinsk litteratur. Trykksted nevnes ikke i listingen av Woldenbergs bøker, men de fleste av bøkene i Blumenthals og Dons' samlinger kom fra Tyskland, deriblant Leipzig og Frankfurt (am Main eller an der Oder). Flere av Dons' medisinske bøker kom også fra Nederland, i særlig grad Amsterdam og Leiden. Disse områdene var da også blant de viktigste intellektuelle og kommersielle sentrene i perioden. «Bestselgerne» i mitt materiale var derfor i utgangspunktet primært skrevet av tyske og nederlandske forfattere (tab 1). Enkelte engelske og danske leger ser likevel ut til å ha vært populære, og av danske leger gjelder dette ikke minst medlemmer av den prominente Bartholin-familien, spesielt Thomas og Caspar d.e. (1585-1629).

Selv om bøkene kom fra spesifikke nettverksområder, speiler ikke boksamlingene noe radikalt brudd mellom «gammelt» og «nytt»: Et viktig trekk ved boksamlingene er bøkenes relativt høye alder. Både i Blumenthals og Dons' boksamlinger, der trykkeår nevnes, er de fleste av bøkene 50-100 år gamle. Flere av bøkene var dessuten skrevet av forfattere fra antikken. Også et svært høyt antall medisinske forfattere listes i de forskjellige protokollene: I Blumenthals boksamling, for eksempel, er hele 90 forskjellige forfattere representert.

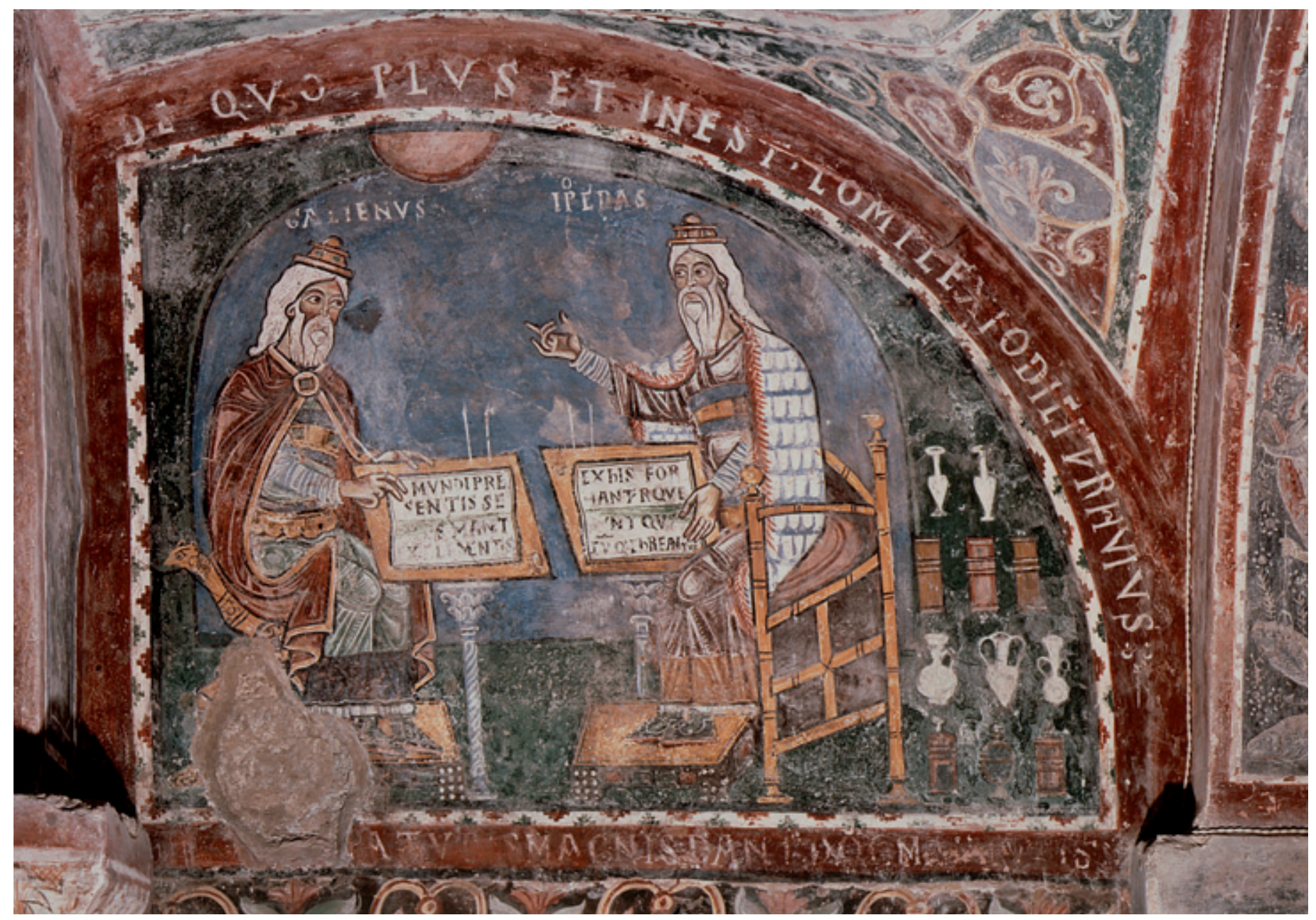

Figur 1 Galen og Hippokrates fremstilt som apoteker og lege i krypten i Domkirken i Anagni i Italia, freske fra 1200-tallet. Foto akg-images/SCANPIX 


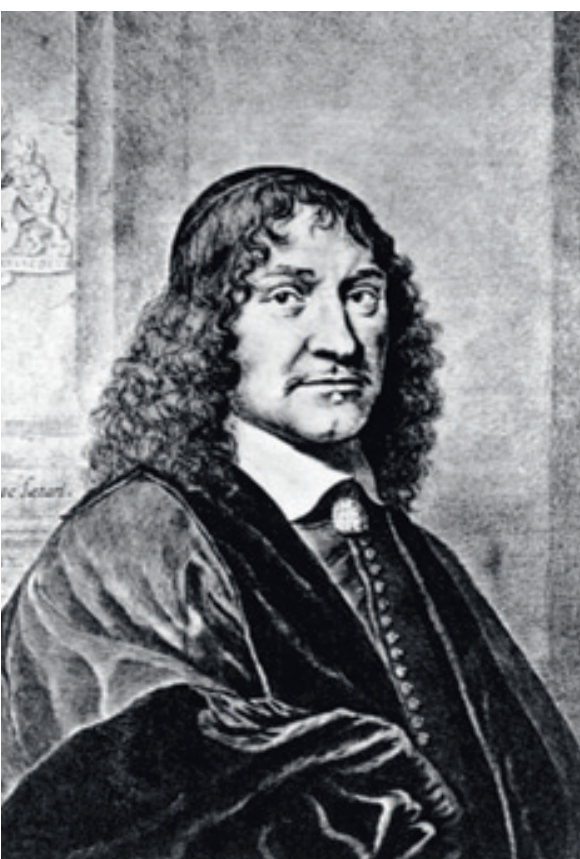

Figur 2 Franciscus Sylvius (1614-72). Foto Science Photo Library/GV-Press/NordicPhotos

Samlingene dekker også mange forskjellige emner. Alle tre eide bøker om botanikk, farmasi og anatomi. Den tyske legen Paul Amman (1643-91), professor i medisin, botanikk og fysiologi i Leipzig, ser ut til å hva vært spesielt populær. Hans bøker om botanikk og farmasi opptrer i alle de tre boksamlingene. Også de nederlandske kirurgene Paul Barbette (ca. 1620-ca. 1666) og Steven Blankaart (1650-1704) er representert i de tre boksamlingene med anatomiske verk.

\section{Humoralpatologi, iatrokjemi og iatromekanikk}

I boksamlingene finnes flere verk av humoralpatologisk støpning. Lazarus Riverius (1589-1655), den franske kongens livlege, er representert med bøker i alle boksamlingene. Riverius var en sterk tilhenger av humoralpatologien (11 s.193-4). Selv om Thomas Bartholin også er en viktig forfatter $i$ alle de tre boksamlingene, er det hans far Caspar Bartholin den eldres lærebok Institutiones anatomicae som ser ut til å ha nytt størst popularitet (fig 4). Boken, en samling av andre forfatteres anatomiske arbeider, hadde allerede i 1688 utkommet i hele 33 utgaver, og den ble oversatt til fransk, tysk, hollandsk og engelsk (12). Galenske teorier ble brukt som utgangspunkt for Bartholins vurderinger (13).

Alkymien og iatrokjemien er også godt representert i alle samlingene. Bøker av Paracelsus finnes i to av boksamlingene, og det samme gjør verk av flere av hans disipler. En av dem, Oswald Croll (ca. 1560-1609) var en av de første som begynte å anse kjemi og alkymi som to forskjellige kunnskapsområder. Hans Basilica chymica fra 1609 er et eksempel på et verk som opptrer i to av bok-

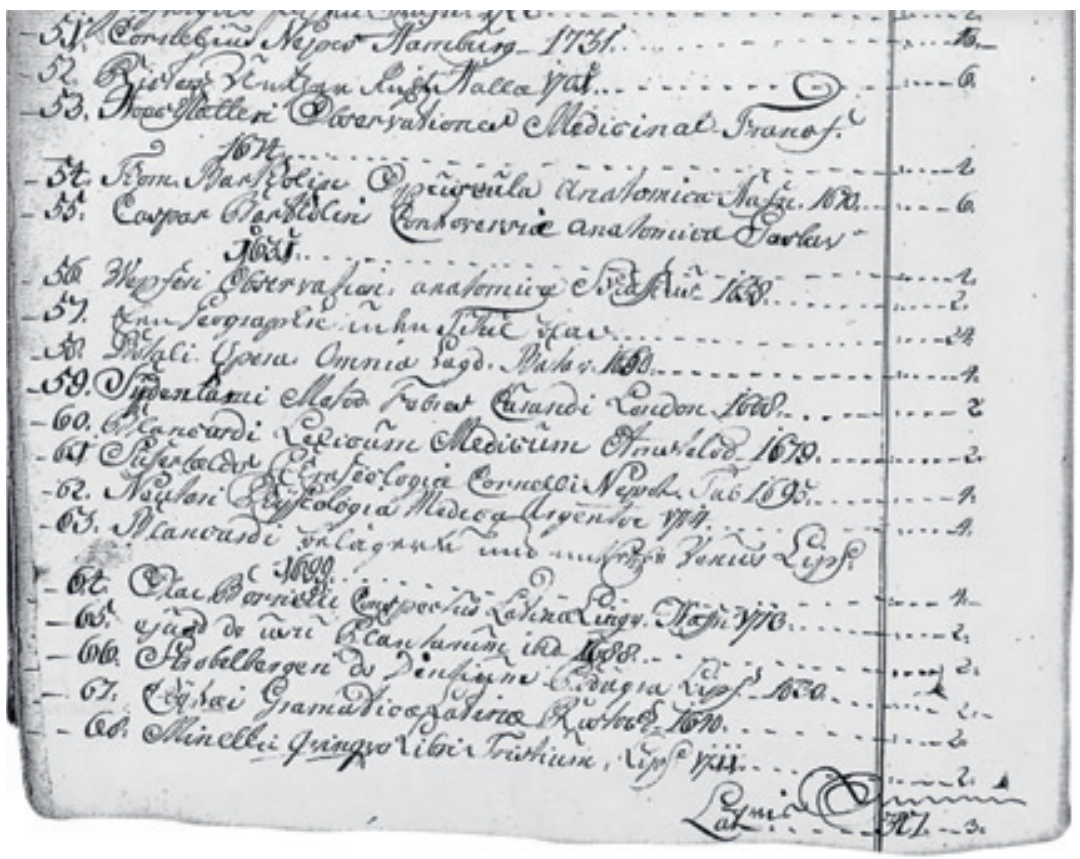

Figur 3 Skifteprotokoll. Statsarkivet i Kongsberg

samlingene. Verket består av tre deler: Del 1 omhandler hermetisk filosofi, del 2 signaturlæren og i del 3 gis det oppskrifter på legemidler fra den paracelsiske tradisjonen (13, s. 347-8). Verk av Franciscus Sylvius (1614-72) er også til stede i flere av boksamlingene. Han regnes for å ha grunnlagt den iatrokjemiske skolen, og studenter fra hele Europa gikk i lære i hans kjemiske laboratorium i Leiden (14). En annen av de mest fremtredende iatrokjemikerne, Joan Baptista van Helmont (1579-1644), er representert med bøker i to av samlingene. Hans tilnærming til medisinen inkluderte både mystisisme og den nye eksperimentelle filosofien, og han klassifiseres ofte som vitalist (3, s. 207-8).

Flere av forfatterne som ser ut til å ha vært populære blant leger i Norge, inntok også en middelvei mellom galenismen og paracelsiske og beslektede teorier. Dette gjelder blant annet Wittenberg-professoren
Daniel Sennert (1572-1637), som er en av de forfatterne som er representert med flest bøker i boksamlingene. Sennerts samlede verker, som Woldenberg eide, var på over 3000 sider, og her diskuteres alt fra giftig luft til okkulte sykdommer (15). Sennert ble en av de største legene i den tyske tradisjonen, og innen 1800 hadde hans verker blitt publisert i 125 forskjellige utgaver (3, s. 207).

Debatten mellom periodens mekanister og vitalister er også reflektert i samlingene: Blumenthal eide åtte av Halle-legen Friedrich Hoffmanns (fig 5) verker, deriblant hans kjente Fundamenta medicinae. Hoffmann var en av de mest leste forfatterne på 1700 -tallet og en av de viktigste representantene for iatromekanikken. Han oppfattet kroppen som en hydraulisk maskin styrt av mekaniske lover og hevdet at nervesystemet var årsak til all bevegelse. Også andre forfattere som tilhørte den mekanistiske tra-

Tabell 1 Forfattere representert med flest medisinske bøker i boksamlingene (1)

Listet $\mathrm{i}$ to samlinger

Listet i tre samlinger
Prosper Alpinius, Giorgio Baglivi, Caspar Bauhin, Johann Joachim Becher, Ole Borch, Thomas Burnet, Girolamo Cardano, William Coles, Oswald Croll, Sigismund Elsholt, Hieronimus Fabricius, Leonhard Fuchs, Johann Rudolf Glauber, Johannes Hartmann, Hippokrates, Friedrich Hoffmann, Johannes Jonston, Johann Juncker, Johann Kunkel, Michael Lyser, Pietro Matthioli, Johann Mays, Richard Morton, Hadrian Mynsicht, Georg Nenteri, Paracelsus, Simon Paulli, Henricus Petraeus, Felix Platter, Petrus Poterius, Henricus Rhegius, Martin Ruland, Angelo Sala, Johann Schenck, Johann Schröder, Franciscus Sylvius, Michael Valentini, Joan van Helmont, Jan van Heurne, Philipp Verheyen, Johan Vesling, Johannes Wittich, Johann Jacob Woyts, Johann Zwelfer

Paul Amman, Caspar Bartholin d.e., Thomas Bartholin, Steven Blankaart, Paul Barbette, Petrus Forestus, Johann Jungken, Lazarus Riverius, Daniel Sennert, Thomas Sydenham, Johann Jacob Waldschmidt, Georg Wolfgang Wedel 


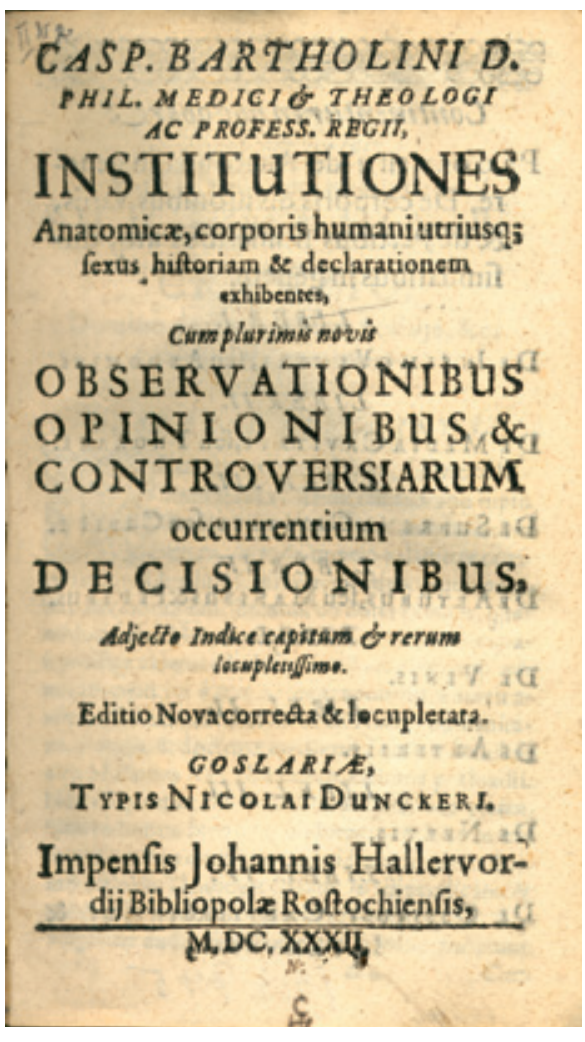

Figur 4 Caspar Bartholin den eldres lærebok Institutiones anatomicae. Utlånt av Universitetsbiblioteket i Bergen

disjonen kan sies å ha vært populære blant leger i Norge, eksempelvis opptrer legene Johan Jacob Waldschmidt d. e. (1644-89) og Georg Wolfgang Wedel (1645-1721) $i$ alle tre samlingene. Wedel var tilsynelatende den første forfatteren som brukte ordet «fysiologi» i den betydning det har i dag. Andre forfattere med et mekanistisk kroppssyn som er representert med flere bøker i boksamlingene, er Henricus Regius

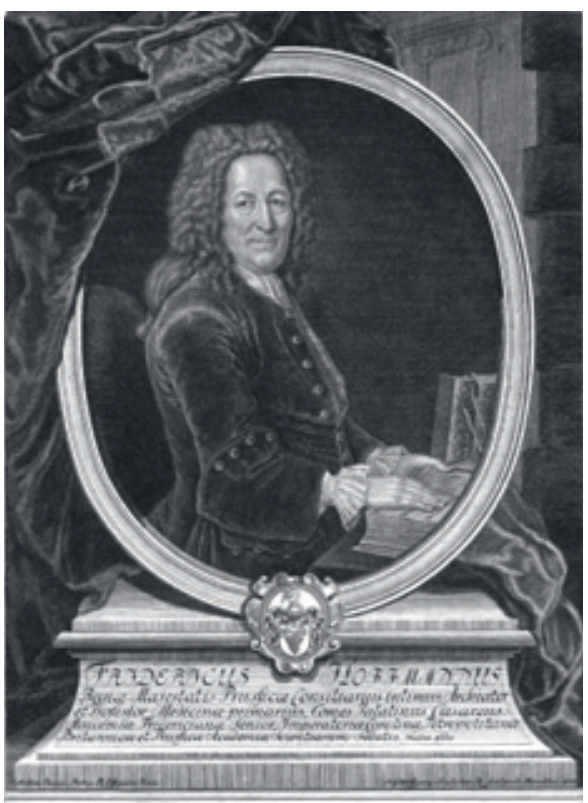

(1598-1679) og Georgio Baglivi (1668-1707). Baglivi hevdet for eksempel at «Gud ser ut til å ha ordnet menneskekroppens proporsjoner i henhold til matematikkens lover» (3, s. 246). Woldenberg eide Baglivis svært kjente De praxi medica. Samlingene inkluderer imidlertid også verk av iatromekanikkens kritikere: Flere av bøkene i Blumenthals samling, deriblant Conspectus chirurgiae og Conspectus formularum medicarum, var skrevet av Johann Juncker (1679-1759), en disippel av vitalisten Georg Ernst Stahl (1659-1743). Stahl, en kollega av den ovenfornevnte Friedrich Hoffmann, hevdet at menneskets bevegelser ikke kunne totalforklares gjennom mekanistiske prinsipper (16).

Flere andre av medisinhistoriens klassikere går også igjen i samlingene. Den «engelske Hippokrates» Thomas Sydenham (1624-89) er representert med forskjellige bøker i de tre boksamlingene. Sydenham vektla at man ved nøye observasjon av pasienter kunne avdekke faste symptomer på sykdommer og dermed forbedre behandlingen av dem. Han praktiserte selv «observasjon og terapi» under studier av epidemiene som brøt ut i London i 1660- og 70årene (17 s.191-2). En annen pestlege ser også ut til å ha vært spesielt populær: Petrus Forestus (1522-97), ofte kalt den «nederlandske Hippokrates», er representert med bøker i alle tre boksamlingene.

\section{Konklusjon}

Hva forteller så disse boksamlingene oss? Et opplagt funn er at alle de tre legene var internasjonalt orientert; bøkene i samlingene kom primært fra Tyskland og Nederland. Alderen på bøkene indikerer dessuten at medisinske teorier i den tidlig moderne perioden beholdt sin aktualitet over lengre tid, i motsetning til i dag der medisinsk kunnskap ofte blir utdatert dersom den overstiger et tosifret tall.

Et annet funn er samlingenes brede orientering, både teoretisk og praktisk. Et høyt antall forfattere listes i de forskjellige samlingene, og disse representerte mange ulike teoretiske overbygninger. Perioden rundt 1700 er da også ofte blitt karakterisert som en eklektisk periode innenfor medisinen. Galen var ikke lenger den ubestridte autoritet, og nye medisinske systemer var blitt lansert uten at noen av dem fikk bli enerådende. I den medisinske praksis var imidlertid humoralpatologien fremdeles viktig, og humoralpatologiske behandlingsprinsipper kom derfor til å sirkulere side om side med iatrokjemiske og iatromekaniske prinsipper. Denne eklektisismen speiles, som vi har sett, også i boksamlingene, der det ikke ser ut til at noen spesifikk lære ble sett på som autoritativ.
Litteratur

1. Dahl G. Questioning religious influence - Private libraries of clerics and physicians in Norway $1650-1750$. Doktoravhandling. Bergen: Seksjon for religionsvitenskap, 2007: 428-9.

2. Johannesen FE, Skeie J. Bitre piller og sterke dråper. Norske apotek gjennom 400 år 1595-1995. Oslo: Norsk farmasihistorisk museum, 1995: 18.

3. Porter R. The greatest benefit to mankind. A medical history of humanity from antiquity to present. London: Fortuna Press, 1999: 229.

4. Ingerslev E. Ambrosius Rhodius og hans hustru. Medicinsk-historiske Smaaskrifter 1916-1917; 14

5. Ehrencron-Müller H. Forfatterlexikon omfattende Danmark, Norge og Island indtil 1814. København: Aschehoug, 1924-35

6. Madsen ST, Sollied O. Medisinsk liv i Bergen. Bergen: Selskabet, 1931: 17.

7. Martsein O. Legeliv i Trondheim. Trondheim stadsfysikats første 238 år, 1661 -1899. Molde: Helped, 1999: 24-9.

8. Catalogus librorum praesertium medicinalium qvas reliqvit Dn. Paul Dons. Trondheim, 1749.

9. Statsarkivet i Bergen. Auksjonsprotokoll nr. 19, 1734-1739: folio 78

10. Statsarkivet i Kongsberg. Skifterettsprotokoll nr. 2, 1739-1745: folio 454a.

11. French R. Medicine before science. The business of medicine from the middle ages to the Enlightenment. Cambridge: Cambridge University Press, 2003: 193-4.

12. Kragh $\mathrm{H}$, red. Fra middelalderlærdom til den nye videnskab 1000-1730. Aarhus: Aarhus universitetsforlag, 2005: 337-40.

13. Fink Jensen M. Fornuften under troens lydighed. Naturfilosofi, medicin og teologi i Danmark 1536-1636. København: Museum Tusculanums Forlag, 2004: 331-4.

14. Margotta R. History of medicine. London: Octopus 2001: 107.

15. Thorndike L. A history of magic and experimental science. Bd. 8. New York, NY: Columbia University Press, 1958: 203-17.

16. Porter R. Blood \& Guts. A short history of medicine. London: Penguin Books, 2003: 67-8.

Manuskriptet ble mottatt 4.7. 2008 og godkjent 15. 10. 2009. Medisinsk redaktør Anne Kveim Lie.

Figur 5 Friedrich Hoffmann (1660-1742) 